\title{
Research on the College English Listening Teaching Mode based on the Associated Guidance Theory
}

\author{
Gao Li \\ Culture And Communication School, Shaanxi University of Science and Technology, \\ Xi'an, Shaanxi,710021 China
}

\begin{abstract}
In this paper, we conduct research on the college English listening teaching mode based on the associated guidance theory. College English is an important course in teaching of universities and the college English listening teaching should also become the important content of the teaching in the colleges and universities. Although under the existing conditions, college listening teaching is faced with the curriculum, teaching mode, teaching evaluation, and many other problems we should also be positive on the future of the English education. Hearing cognitive strategies, specific means students can according to the requirements of listening teaching, institute of information storage and retrieval method in order to solve the problems in the study, such as capturing keywords, capture the nonverbal hints, reasoning, taking notes, etc., it is to measure students to absorb and understand speech materials contained in the important measure of information ability. Under this guidance, we propose the new idea of associated guidance theory assisted teaching mode that will gain better performance.
\end{abstract}

Keywords- College English, Listening Teaching, Associated Guidance Theory, English Education.

\section{Introduction}

College English has an important position in the process of higher education personnel training. It is not only a public foundation course, there are rich in general meaning, the outlook of college students to help students to understand the world multicultural has irreplaceable function. In this context, discuss the general meaning of the college English and its implementation strategy to promote college English teaching and the reform of the general education has important practical value, to improve the quality of talent cultivation in colleges and universities has the profound significance [1-2].

According to the theoretical review, the primary challenges and the principles of the contemporary English education could be summarized as the follows. (1) Because English is a relatively boring subject, students in the classroom teaching process is only in the face of real or simulated language context can have good logical ability of organization, and through the understanding of the language situation to master contains information and materials. (2) In teaching English to students, we often emphasize is to cultivate students ability to use the English to solve the problem of professional, but belongs to a language as English class teaching course, so, in the process of teaching to cultivate the students' language ability is also very important. (3) Due to different students basic knowledge in the English learning skills and learning ability has certain differences, so teachers in the setting problem, should ensure that its difficulty has great flexibility that is the best way to setup method from easy to difficult, step by step, so that every student can master knowledge through problem teaching content. (4) When teachers want to help students consolidate what they have learned knowledge and inspire and guide students to learn the new knowledge of English, teachers should set up those can effectively cultivate students creative ability and open questions of divergent thinking [3-4].

Currently, in the course of the college English teaching listening comprehension is one of the most difficult skills to master a language and one 
aspect is also learning to feel the most helpless. How to eliminate negative emotions for English learners listening comprehension and to improve the English listening ability has become an urgent need in the college English teaching research as well as are the major factors in the improvement of listening level language factors and non-language factors. The improvement of listening comprehension besides must have the certain language knowledge, cultural background knowledge, common sense, and basic knowledge of various disciplines, it is important, must also be skilled to master and use the language skills, namely listening skills. Although listening comprehension mainly rely on basic auditory information, related words such as visual and auditory information also has a lot of help for listening comprehension as the listener can be according to the different language features and various language clues.

Under this background, to deal with the mentioned challenges, we conduct research on the college English listening teaching mode based on the associated guidance theory.

\section{PRINCIPLES OF TEACHING LISTENING COMPREHENSION}

Let students understand how foreigners speak English and build students sensitivities.

- All teachers can do is give them some guidelines provide an opportunity for meaningful practice and trust they will learn these things for themselves. ( Buck, 1995)

Figure 1. The General Principles of the College English Listening

\section{Our Proposed Methodology}

The Associated Guidance Theory. Under certain circumstances, how to correctly grasp the analysis of word meaning, we must through the appropriate context for correlation, and then according to the actual circumstances of the discourse and the context for associated reasoning, and then translate.
Relevance theory is a theory of the cognitive pragmatics, it from the perspective of cognition, the information in the basic study of language communication reasoning process, describes the cognitive process of each word and the relevance of discourse itself and the context. Relevance theory is in the process of cognition is trying to get the greatest cognitive effect with the smallest input.

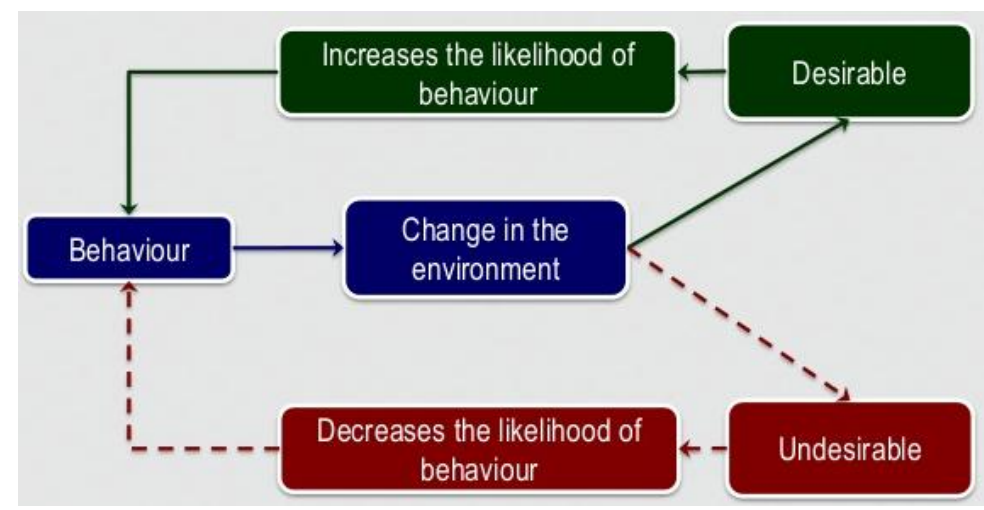

Figure 2. The Architecture Illustration of the Associated Guidance Theory 
Relevance theory is the important contribution to the understanding of the discourse is the process of its context as is the discourse information and on the basis of the construction of relevant context the result of the interaction. According to Sperber and Wilson's point of view, core of communication between human brain mechanisms is a kind of ability to reasoning based on people's behavior. Verbal communication includes two different kinds of representation: semantic representation in the form of propositions and thinking and there is no strict one-to-one relationship between the two. The view of the relevance theory of communicative behavior is a kind of intention theory. The speaker wants to convey information and obedient people would need to identify the intention of the speaker to pass this information, or to identify speaker's communicative intention. This needs to the communication behavior of the speaker and the hearer to implement the behavior of the relationship between the core intentions of the inference, which is obedient people need from the perspective of the communicative purpose to explain the behavior of the speaker [5-6].

People's cognitive environment includes the physical environment and cognitive ability. The two parts of a common culture namely total nuclear provides the communication between people of the different cultures. Physical environment, however, it is not the same and different cognitive makes things related in a culture in another culture is not necessarily related. The different culture will lead to the incomplete information acquisition, information error or complete communication barriers.

The social dimension of relevance theory could be summarized as follows. (1) Relevance theory is different from the encoding, decoding mode of the communication, which sees communication as a meaning between speakers and as hearers replication process. From the angle of the code model, the communication is a process of social interaction, but it has insisted on the orientation of the symbols, coders only need to generate a certain symbols and decoding is also need to pay attention to sign. (2) Success depends on people in characterization of the complex social environment ability. Cognitive environment is different because of the physical environment and cognitive differences while actually cognitive environment is also in the social dimension as the forerunner. (3) Communication is to change the both sides of the general mutual cognitive environment, are realized by express behavior. Communication people will only pay attention to those words or information is relevant for them. By implementing certain express communicative behavior, the speaker hopes to derive his intentions the hearer is to pay attention to his psychological state.

The English Listening Teaching Mode. Listen to is the main way to obtain information and the language feeling is an important way to improve other skills at the same time. Listening practice with the purpose of the state is not understand how many words or sentences, also is not how many times can pass the listening test. Listening state is in the process of listening, listening skills and strategies to develop and nurture while learn to acquire and process information. By listening to, and master new knowledge, rich experience, expanded vision and cultivate the ability to think in English, in order to improve the ability to use English in a real environment. 


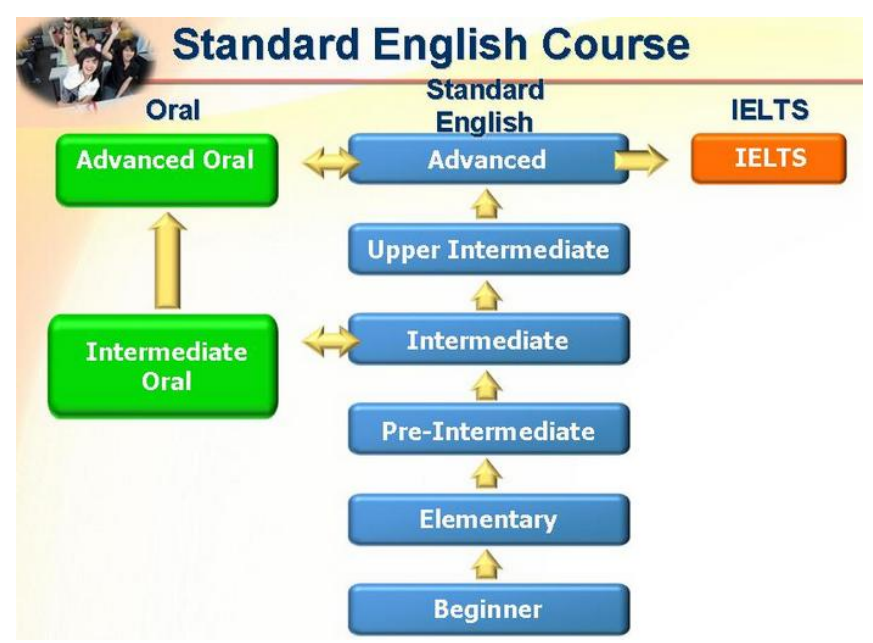

Figure 3. The Enhanced Architecture of English Listening Teaching Mode

At present a lot of college English listening course in the colleges and universities to improve the hardware facilities, but pay attention to enough, for listening teaching of college English listening class has more than in the hall of non-English major become a mere formality, as much appreciate for movies in class, the teaching material pan-listens, exam is in-class test, the teaching effect is not very ideal. Therefore, we propose the listed countermeasures for enhancement.

- To stabilize the mood, to do in the listening material arrangement from shallow to deep, from easy to difficult, step by step transition while also develop the good learning attitude, correctly handling the difficulties and setbacks in the hearing training, enhance self-confidence.

- Teachers can use multimedia devices, random monitored students retelling, timely correcting any errors. It is not only the basis of poor students receive timely improvement opportunities, and to achieve the better students [7].

- By using the multimedia network platform, boring classroom listening teaching is opportunity from a single "scripted" to give priority to with the teaching materials, all kinds of multiple themes genre content in the form of flexible hand in hand.

- In a certain situation or social and cultural background, using the necessary learning resources, through the communication with teachers and learning partners, collaboration, and finally to obtain the knowledge in the form of the meaning construction. In achieving this goal, teachers should give students a task list in advance, to design the real task.

The Dictation Training. Listening skills as the basis of cultivating communicative competence, in the human language communication is a voice of receiving information decoding process, refers to the thinking through the brain to receive from the outside world to the sound waves to decode and understand the meaning of each other words, in order to further organize information coding, begin the next round of information transmission and receiving paving. Therefore, listening comprehension in language communication plays a structure connecting ecosystem and individuals, the important role of processing information. Dictation process is a complex process of neurotransmission, schema theory is that people understand the new information is according to the existing knowledge to explain in mind, a new type of information should be completed with the existing schema matching to 
the smooth realization of basic information processing, to fill with data storage space, to concrete implementation scheme from the viewpoint of information processing memory is to the brain to the outside input information coding. In storage and extraction process, the efficiency of the information transmission depends on the traffic load and channel capacity and the relationship between the traffic load is equal to the transmission efficiency is highest when the channel capacity [8].

At the start stage of hearing students, discussing whether the implementation of "top-down" or "bottom-up" before listening teaching strategy, first to investigate the characteristics of the teaching object. In other words, most of their listening comprehension on the first link will appear problem to make the whole process chain interruption, unable to start the existing graphic, and compared with the effective information, related to the response. Dictation consists of two activities in listening and the writing. Dictation process is to understand the play or read by the process of language information and record it down. This process requires students in a short time fully mobilize the existing knowledge such as vocabulary, pronunciation, grammar, translation and instantaneous or short-term memory and shorthand skills. Part before and talked about a variety of adverse factors will affect all kinds of the knowledge and ability to mobilize students, seriously hinder improvement of the students dictation ability, dictation ability to make students have really improved, must overcome unfavorable factors.

To deal with the challenges shown as above, we should follow the listed suggestions. (1) Advocate students to grope for dictation skills and introduce dictation skills appropriately. Mainly by students in the usual dictation skills acquired in the process of learning to fumble, to find a set of suitable for your dictation skills. (2) To cultivate students quickly decipher, as rapid memory and the ability to quickly record. Speed of the training is very important for dictation ability. Practice there are three main types: short retelling, phrase translation repeat, do the dictation. This approach can not only train students' ability of fast decoding, and can train students' ability in instantaneous memory. In listening class using this method can make students spirit is in nervous condition, the brain active, thus improves the quality of the classroom listening teaching. (3) Supervise the students extracurricular listening more to write. To train the ability of the dictation, listening course alone is not enough. Students must also extracurricular listening more to the write, practice. While listening to the broadcast content records, choose content more clear recording of dictation. Dictation is to answer each other, don't understand where listen to again and again and try to imitate the standards English pronunciation and intonation.

\section{Conclusion}

In this paper, we conduct research on the college English listening teaching mode based on associated guidance theory. English listening is higher school is a compulsory course for students majoring in English. The teaching of listening course aims at developing students' listening ability, improve their listening level, and develop good listening habits, stimulate their interest in listening, obtain certain information, increase knowledge, expanding horizons, experience bring them the pleasure of hearing, harvest and success and some problems existing in the current college listening class, could not fully achieve the purpose of this. Under this requirement, we propose the novel perspective on the college English listening teaching mode with the integration of associated guidance theory that is innovative and meaningful. In the future research, we will test the effectiveness of our method with survey. 


\section{Acknowledgement}

This research is financially supported by the special research project in Shaanxi province department of the education (NO. 14JK1069). The project name is: Research on the College English Listening Teaching Mode based on the Associated Guidance Theory.

\section{References}

[1] Wang, XiYan, and TianHao Wang. "Indirect speech acts applied to the multimedia-assisted college English listening teaching." Computational Intelligence in Industrial Application: Proceedings of the 2014 Pacific-Asia Workshop on Computer Science in Industrial Application (CIIA 2014), Singapore, December 8-9, 2014. CRC Press, 2015 .

[2] Wang, Xiyan, and Tianhao Wang. "Teaching strategies of English listening assisted by multimedia." Advances in Future Manufacturing Engineering: Proceedings of the 2014 International Conference on Future Manufacturing Engineering (ICFME 2014), Hong Kong, December 10-11, 2014. Vol. 2. CRC Press, 2015.
[3] He, Xiaoyu. "Non-English Majors' Listening Teaching based on Lexical Chunks Theory and Schema Theory." English Language Teaching 9.2 (2016): 142.

[4] Zhichao, Long, and Bi Jia. "An Analysis of CBI-Based College English Listening Teaching for English Majors." The Science Education Article Collects 5 (2014): 027.

[5] Yongjin, Hu. "An Empirical Research Testing the Effects of Multimodality on English Listening Teaching." Group 1.30 (2013): 18-60.

[6] ZHANG, Zhi-jie, and Wei-xiu YANG. "Teaching Strategies of College English Listening in the Light of Computer-based CET-4-From the Angle of College English Band Four Test." Journal of Beihua University (Social Sciences) 1 (2012): 038.

[7] SUN, Jing, and Jing-yun ZHOU. "Report on the Teaching Reform of Online Multimedia Listening and Speaking Class." Journal of Heilongjiang College of Education 2 (2014): 073.

[8] Siegel, Joseph, and Aki Siegel. "Empirical and attitudinal effects of bottom-up listening activities in the L2 classroom." ELT World Online 5 (2013): 1-25. 